\title{
NEW MOLECULAR TARGETS IN THE THERAPY OF ARTHROSIS PATIENTS
}

\section{Pelin Ana-Maria², Fulga Simona ' , Ghiciuc Gristina Mihaela ', Lupussoru Cătălina Elena'}

1 "Grigore T. Popa" University of Medicine and Pharmacy of Iasi, Romania.

2 "Dunarea de Jos" School of Medicine and Pharmacy of Galati, Romania.

Department of Pharmacology, Faculty of Medicine, "Grigore T. Popa" University of Medicine and Pharmacy Iasi, Romania email: cristina.ghiciuc@umfiasi.ro

\begin{abstract}
Introduction: Arthrosis represents the progressive degeneration of the joint cartilage, accompanied by the narrowing of the articular space and inflammation, which affects $70 \%$ of the population after the age of 60. Research purpose: This paper reviews the opportunity of using proinflammatory cytokine inhibitors as a means of stopping the progress of arthrosis. Material and method: As a result to a research into various clinical trial registers (Arthritis Clinical Trials, Clinical Research and Drug Information) and on specialized e-platforms, 5 randomized, multicentric double-blind clinical studies have been identified, which monitored the efficiency of various biological molecules in the treatment of arthrosis (etanercept, adalimumab, litikizumab, fasinumab and tanezumab). Results: The current pharmacological interventions consist mainly in the prescription of analgesics (acetaminophen, opioid analgesics), non-steroidal and chondroprotective antiinflammatories. The proinflammatory cytokine inhibitors are already widely used in the inflammatory joint diseases, such as the rheumatoid polyarthritis. Their introduction into the treatment of arthrosis blocks the disease's etiopathogenic mechanisms. Discussions: Arthrosis physiopathology involves a series of systemic, biological, biochemical factors, molecular and enzymatic processes that generate minimum inflammation. IL$1 \mathrm{~b}$ and TNF- $\alpha$ are two major cytokines produced by the synovial cells and chondrocytes, which are involved in the destruction of the cartilage matrix by stimulating the production of proteolytic enzymes (MMP and aggrecanase). Conclusions: The utilisation of proinflammatory cytokine inhibitors in arthrosis represents a therapeutic option that requires studies in order to establish whether the introduction of proinflammatory cytokine inhibitors in arthrosis therapy might slow down the disease's etiopathogenic mechanisms.
\end{abstract}

Keywords: arthrosis, cytokines, proinflammatory cytokine inhibitors

\section{Introduction}

Osteoarthritis (OA), one of the most known musculoskeletal disorders, is affecting more than $70 \%$ of people over 60 years old (1). For a long time, it was considered only a progressive degenerative joint disease as part of the clinical syndrome, generating pain and invalidity in the elders. The chronic forms of OA are more and more considered as inflammatory diseases and occur at younger ages.

According to current guidelines for arthrosis therapy, pharmacologic interventions have addressed the symptomatology and mainly consisted in the prescription of analgesics (acetaminophen, opioid analgesics), non-steroidal anti-inflammatories and chondroprotectors (9). All the therapeutic strategies used nowadays focus on fighting the inflammation. The classical pharmacological therapy, although have analgesic effects, does not prevent the progression of degenerative modifications of the joint cartilage (10). The biologic therapy is a flourishing area for researches in the field of rheumatoid arthritis (RA) and of ankylosing spondylitis (AS).

Purpose of research: There is lack of knowledge about the physiopathological mechanisms involved in the occurrence or progression of OA, due to the lack of data on the development and maintenance of the cartilage 
integrity, which is affected in osteoarthritis (2). The increase of cytokines production and of growth factors production characteristic to OA is usually associated with modifications in other articular structures: degradation of articular cartilage, synovial cells and subchondral bone (2). The fragments of proteoglycans and collagen from the cartilage surface, occurred due to cracks and erosions, entails the release of these fragments into the synovial liquid. After a stage when the cartilage increases the proteoglycan production in order to repair the degradation, cartilage resorption begins. To the cartilage resorption, the synovial inflammation caused by the cartilage degradation products being released into the synovial liquid is added, the expression of which is the activation of VEGF, NF-kB, COX2, TGF- $\beta$, TNF- $\alpha$, and IL- $1 \beta$. In this context, this paper reviews the opportunity of using proinflammatory cytokine inhibitors as a means of stopping the progress of arthrosis.

\section{Materials and methods}

As a result to a research into various clinical trial registers (Arthritis Clinical Trials, Clinical Research and Drug Information) and on specialized e-platforms, 5 randomized, multicentric double-blind clinical studies (2024) have been identified, which monitored the efficiency of various biological molecules in the treatment of arthrosis (etanercept, adalimumab, litikizumab, fasinumab and tanezumab).

\section{Results}

The prescription of analgesics (acetaminophen, opioid analgesics), nonsteroidal and chondroprotective antiinflammatories represents the current main pharmacological therapy. The proinflammatory cytokine inhibitors have a widespread use in the inflammatory musculoskeletal diseases, such as the rheumatoid polyarthritis. Their introduction into the treatment of arthrosis blocks the disease's etiopathogenic mechanisms.

Only 5 randomized, multicentric doubleblind clinical studies (17-21) which monitored the efficiency of various biological molecules in the treatment of arthrosis have been identified (Table 1).

Despite all these, there is no biologically validated therapy for OA (11). Even if OA has been considered to a large extent a "wearand-tear disease", it involves "low-level" inflammation and the increase in the number of

Table. 1. Randomized, multicentric double-blind clinical studies (17-21) which monitored the efficiency of various

biological molecules in the treatment of arthrosis. Abbreviations: OA, osteoarthritis; RCT, randomized placebocontrolled trial; VAS, Visual Analog Scale; WOMAC, Western Ontario \& McMaster Universities arthritis index, PGA, patient global assessment.

\begin{tabular}{|c|c|c|c|c|c|c|}
\hline STUDY & Indication & Study design & $\begin{array}{l}\text { Route of } \\
\text { administration }\end{array}$ & $\begin{array}{l}\text { Main } \\
\text { end point } \\
\text { (follow-up) }\end{array}$ & $\begin{array}{l}\text { Outcome } \\
\text { Results }\end{array}$ & $\begin{array}{l}\text { Adverse } \\
\text { events }\end{array}$ \\
\hline $\begin{array}{l}\text { Ohtori et al. } \\
2015\end{array}$ & \begin{tabular}{|l|} 
Knee OA \\
(moderate \\
and severe)
\end{tabular} & $\begin{array}{l}\mathrm{n}=39 \\
\text { prospective study }\end{array}$ & $\begin{array}{l}\text { Etanercept } \\
\text { Intra-articular }\end{array}$ & \begin{tabular}{|l|} 
VAS \\
WOMAC \\
4 week \\
\end{tabular} & Significant pain relief & No events \\
\hline $\begin{array}{l}\text { Aitken et al. } \\
2018\end{array}$ & $\begin{array}{l}\text { Erosive } \\
\text { hand OA }\end{array}$ & $\begin{array}{l}\mathrm{n}=51 \\
\text { randomized, double- } \\
\text { blind, placebo- } \\
\text { controlled, crossover } \\
12 \text { weeks }\end{array}$ & $\begin{array}{l}\text { Adalimumab } \\
\text { subcutaneous }\end{array}$ & VAS & $\begin{array}{l}\text { No effect on pain, synovitis } \\
\text { (detected on magnetic } \\
\text { resonance imaging) or on } \\
\text { bone marrow lesions }\end{array}$ & $\begin{array}{l}\text { Not } \\
\text { mentioned }\end{array}$ \\
\hline $\begin{array}{l}\text { Birbara et } \\
\text { al., } 2018\end{array}$ & $\begin{array}{l}\text { Knee or Hip } \\
\text { OA }\end{array}$ & $\begin{array}{l}n=39 \\
\text { a placebo-controlled trial }\end{array}$ & $\begin{array}{l}\text { Tanezumab } \\
\text { subcutaneous / } \\
\text { intravenous }\end{array}$ & WOMAC & $\begin{array}{l}\text { Similar efficacy and safety } \\
\text { for both routes }\end{array}$ & $\begin{array}{l}\text { Not } \\
\text { mentioned }\end{array}$ \\
\hline $\begin{array}{l}\text { Fleischmann } \\
\text { et al. (2019) }\end{array}$ & Knee OA & $\begin{array}{l}n=350 \\
\text { phase II trial }\end{array}$ & $\begin{array}{l}\text { Lutikizumab } \\
\text { subcutaneous }\end{array}$ & WOMAC & $\begin{array}{l}\text { Limited improvement in } \\
\text { the WOMAC pain score } \\
\text { and no effect on synovitis }\end{array}$ & $\begin{array}{l}\text { Not } \\
\text { mentioned }\end{array}$ \\
\hline $\begin{array}{l}\text { Dakin et al., } \\
2019\end{array}$ & $\begin{array}{l}\text { Hip or Knee } \\
\text { OA }\end{array}$ & $\begin{array}{l}\mathrm{n}=421 \\
\text { randomized, phase IIb/III } \\
\text { double-blind, placebo- } \\
\text { controlled study }\end{array}$ & $\begin{array}{l}\text { Fasinumab } \\
\text { intravenously }\end{array}$ & $\begin{array}{l}\text { WOMAC/ } \\
\text { PGA }\end{array}$ & $\begin{array}{l}\text { Pain relief and } \\
\text { improvement of function }\end{array}$ & $\begin{array}{l}\text { Not } \\
\text { mentioned }\end{array}$ \\
\hline
\end{tabular}


the blood vessels and nerves (12). This discovery focused the efforts of researchers to develop the biological therapy useful for the treatment of chronic forms of OA and having as targets the pro-inflammatory cytokines and other factors from the articular cartilage, synovial cells and subchondral bone (13). Nowadays, international fora elaborated arthrosis therapy guidelines. American College of Rheumatology set forth the pharmacologic and non-pharmacologic therapy for the knee, hip and hand arthrosis in 2012 (14). These recommendations rely on the consensus judgment of experts belonging to various specializations, who processed the available evidence relating to the therapy and assessed the advantages and the potential negative effects of the therapies.

Osteoarthritis Research Society International (OARSI) established the nonpharmacologic therapy of the hip and knee arthrosis in 2014. OARSI recommends therapies adequate to each arthrosis phenotype that include kinesio-physiotherapy, intra-articular corticosteroids, weight loss in the obese patient, but also acetaminophen, capsaicin, non-steroidal anti-inflammatory drugs (non-selective or cyclooxygenase-2 selective), and duloxetine. $(15,16)$.

American Academy of Orthopaedic Surgeons (AAOS) establishes the nonpharmacologic, pharmacologic and surgical therapy of knee arthrosis in 2014, and EULAR elaborates in 2018 the hand arthrosis therapy guidelines (16).

\section{Discussions}

Arthrosis physiopathological modifications are complex, involving biological and biochemical factors, but also molecular and enzymatic processes that generate minimum inflammation. Proteolytic enzymes (MMP and aggrecanase) activity is stimulated by IL- $1 \beta$ and TNF- $\alpha$, the main cytokines produced by chondrocytes and by the synovial cells, all these contributing to the degradation of the cartilage matrix. IL-1 $\beta$ may be detected in the synovial liquid and in the cartilage matrix affected by arthrosis. TNF- $\alpha$ seems to have an essential role in causing the inflammation of the synovial membrane and the degradation of the cartilaginous matrix. From these mediators, TNF- $\alpha$ and IL- $1 \beta$ (cataboliceffect cytokines) might stimulate their own production, may stimulate the production of other cytokines (IL-6, IL-8, leukocyte inhibitor) by the chondrocytes and by the cells from the synovial fluid. These stimulate the activity of matrix metalloproteinases and the production of PGE2 that will enhance cartilage degradation (2-5). There is important proof to support the key role of IL-1 $\beta$ in the cartilage degradation. IL-1 $\beta$ causes the destruction of cartilage matrix by the release of proteolytic enzymes degradation (MMPs, aggrecanase). IL-1 $\beta$ also block the normal production of the cartilage matrix components (such as type II collagen, aggrecanes) (5). Concurrently, TNF- $\alpha$ has an essential role in causing inflammation at the level of synovial membrane and in the mediation of the cartilaginous matrix processes. Macrophages produce TNF- $\alpha$, which is involved in the regulation of chrondrogensis (6). TNF- $\alpha$ also may cause chondrocyte apoptosis (7). $\beta$-NGF (Nerve growth factor) is a protein identified within the synovial membrane and liquid of the joints affected by both rheumatoid polyarthritis and arthrosis. $\beta$-NGF interacts with the tyrosine receptors, thus modifying the vanilloid-like pain receptors' phosphorylation. This protein has initially been identified in the central nervous system and appears to be responsible for the transmission of pain impulses in many diseases (8).

The physiopathology of arthrosis is associated with a series of systemic modifications, biological parameters and biochemical factors alterations, molecular and enzymatic processes generating inflammation. Although the inflammationisconsidered to be minimum, the two major cytokines, IL-1 $\beta$ and TNF- $\alpha$, are produced by the synovial cells and by chondrocytes, which are responsible of the destruction of the cartilage matrix by the stimulation of the proteolytic enzymes' production (MMP and aggrecanase). IL-1b can be detected within the synovial liquid and the extracellular matrix of the joints with arthrosis. TNF- $\alpha$ appears to have an essential role in the inflammatory modifications at the level of synovial membrane and in the destruction of the cartilaginous matrix. The therapeutic use of 
cytokine inhibitors in OA is based on the effect on variable degrees of inflammation present in OA, especially at the level of synovial membrane, but its role might have been overrated. The synovitis degree may fluctuate in time at the same patient. Patients displaying signs of inflammation, such as warm and swollen joints, large quantities of synovial liquid, and subsequent high pain levels than the patients with the so-called 'dry joint', might be selected for further studies with proinflammatory cytokine inhibiting drugs. The inhibition of a single cytokine may not enough to reduce the inflammation in OA. In the future studies with biological agents, researchers should consider several factors: administration path; number and frequency of injections; patients' selection; disease heterogeneity (including the stage and whether there are atrophic or hypertrophic forms); presence of inflammation. The therapy's risk-benefit ratio is of particular importance. Although the justification exists, the available clinical data are not enough to endorse the current use of biological therapy for patients with OA. The clinical studies' results indicate that the complex mechanisms behind the pain from $\mathrm{OA}$ is caused the pro-inflammatory cytokines, but future researches must be done in the direction of disease retarding molecules, or for those acting as analgesics. Despite all these, there is a glimpse of hope for the use of biological agents in the therapy of OA. The pro-inflammatory cytokine inhibitors might represent a new therapeutic option in OA, but further clinical studies are needed. The introduction of proinflammatory cytokine inhibitors as a way of stopping the progress of arthrosis requires the identification of the inclusion criteria for the patients who might benefit from such therapies, the establishment of the optimum moment to initiate the therapy and the optimum administration path (systemic vs intraarticular).

\section{Eonclusions}

The utilisation of proinflammatory cytokine inhibitors in arthrosis represents a therapeutic option that requires studies in order to establish whether the introduction of proinflammatory cytokine inhibitors in arthrosis therapy might slow down the disease's etiopathogenic mechanisms.

\section{References}

1. Johnson VL, Hunter DJ. The epidemiology of osteoarthritis. Best Pract Res Clin Rheumatol. 2014 Feb;28(1):5-15.

2. Pelletier JP, Martel-Pelletier J, Abramson SB. Osteoarthritis, an inflammatory disease: potential implication for the selection of new therapeutic targets. Arthritis Rheum. 2001 Jun;44(6):1237-47.

3. Bemer P, Leger J, Milin S, Plouzeau C, Valentin AS, Stock N, et al. Histopathological Diagnosis of Prosthetic Joint Infection: Does a Threshold of 23 Neutrophils Do Better than Classification of the Periprosthetic Membrane in a Prospective Multicenter Study? J Clin Microbiol. 2018 Sep;56(9).

4. Chevalier X, Eymard F, Richette P. Biologic agents in osteoarthritis: hopes and disappointments. Nat Rev Rheumatol. 2013 Jul;9(7):400-10.

5. Goldring SR, Goldring MB. The role of cytokines in cartilage matrix degeneration in osteoarthritis. Clin Orthop Relat Res. 2004 Oct(427 Suppl):S27-36.

6. Blom AB, van Lent PL, Holthuysen AE, van der Kraan PM, Roth J, van Rooijen N, et al. Synovial lining macrophages mediate osteophyte formation during experimental osteoarthritis. Osteoarthritis Cartilage. 2004 Aug;12(8):627-35.

7. Kapoor M, Martel-Pelletier J, Lajeunesse D, PelletierJP,FahmiH. Role of proinflammatory cytokines in the pathophysiology of osteoarthritis. Nat Rev Rheumatol. 2011 Jan;7(1):33-42.

8. Chevalier X, Eymard F. Anti-IL-1 for the treatment of OA: dead or alive? Nat Rev Rheumatol. 2019 Apr;15(4):191-2.

9. Colombini A, Perucca Orfei C, Kouroupis D, Ragni E, De Luca P, Vigan OM, et al. Mesenchymal stem cells in the treatment of articular cartilage degeneration: New biological insights for an old-timer cell. Cytotherapy. 2019 Dec;21(12):1179-97.

10. Jaswal AP, Bandyopadhyay A. Re-examining osteoarthritis therapy from a developmental biologist's perspective. Biochem Pharmacol. 2019 Jul;165:17-23. 
11. Jaswal AP, Ray A, Bandyopadhyay A. Etiology and Treatment of Osteoarthritis: A Developmental Biology Perspective. In: Mukhopadhyay A, editor. Regenerative Medicine: Laboratory to Clinic. Singapore: Springer Singapore; 2017. p. 17-42.

12. Scanzello CR. Role of low-grade inflammation in osteoarthritis. Curr Opin Rheumatol. 2017 Jan;29(1):79-85.

13. Kloppenburg M, Ramonda R, Bobacz K, Kwok WY, Elewaut D, Huizinga TWJ, et al. Etanercept in patients with inflammatory hand osteoarthritis (EHOA): a multicentre, randomised, double-blind, placebocontrolled trial. Ann Rheum Dis. 2018 Dec;77(12):1757-64.

14. Hochberg MC, Altman RD, April KT, Benkhalti M, Guyatt G, McGowan J, et al. American College of Rheumatology 2012 recommendations for the use of nonpharmacologic and pharmacologic therapies in osteoarthritis of the hand, hip, and knee. Arthritis Care Res (Hoboken). 2012 Apr;64(4):465-74.

15. McAlindon TE, Bannuru RR, Sullivan $\mathrm{MC}$, Arden NK, Berenbaum F, BiermaZeinstra SM, et al. OARSI guidelines for the non-surgical management of knee osteoarthritis. Osteoarthritis Cartilage. 2014 Mar;22(3):363-88.

16. Parker DA, Scholes C, Neri T. Non-operative treatment options for knee osteoarthritis: current concepts. Journal of ISAKOS: Joint Disorders \&amp; Orthopaedic Sports Medicine. 2018;3(5):274-81.

17. Ohtori S, Orita S, Yamauchi K, Eguchi Y, Ochiai N, Kishida S, et al. Efficacy of Direct Injection of Etanercept into Knee Joints for Pain in Moderate and Severe Knee Osteoarthritis. Yonsei Med J. 2015 9/;56(5):1379-83.

18. Aitken D, Laslett LL, Pan F, Haugen IK, Otahal P, Bellamy N, et al. A randomised double-blind placebo-controlled crossover trial of HUMira (adalimumab) for erosive hand OsteoaRthritis - the HUMOR trial. Osteoarthritis Cartilage. 2018 Jul;26(7):8807.

19. Fleischmann RM, Bliddal $H$, Blanco FJ, Schnitzer TJ, Peterfy C, Chen S, et al. A Phase
II Trial of Lutikizumab, an Anti-Interleukin1alpha/beta Dual Variable Domain Immunoglobulin, in Knee Osteoarthritis Patients With Synovitis. Arthritis Rheumatol. 2019 Jul;71(7):1056-69.

20. Birbara C, Dabezies EJ, Jr., Burr AM, Fountaine RJ, Smith MD, Brown MT, et al. Safety and efficacy of subcutaneous tanezumab in patients with knee or hip osteoarthritis. J Pain Res. 2018;11:151-64.

21. Dakin P, DiMartino SJ, Gao H, Maloney J, Kivitz AJ, Schnitzer TJ, et al. The Efficacy, Tolerability, and Joint Safety of Fasinumab in Osteoarthritis Pain: A Phase IIb/III DoubleBlind, Placebo-Controlled, Randomized Clinical Trial. Arthritis Rheumatol. 2019 Nov;71(11):1824-34. 